\title{
Impact of the SARS-CoV-2 pandemic on trauma care: a nationwide observational study
}

\author{
Mitchell L. S. Driessen ${ }^{1}$ (1) - Jan C. van Ditshuizen ${ }^{2} \cdot$ Job F. Waalwijk $^{3} \cdot$ Gerrita van den Bunt $^{1} \cdot$ Frank F. A. IJpma $^{4}$. \\ Inge H. F. Reininga ${ }^{5}$ - Audrey A. Fiddelers ${ }^{3} \cdot$ Karin Habets $^{6}$. Paulien C. M. Homma ${ }^{7}$. Marleen H. van den Berg ${ }^{8}$. \\ Frank W. Bloemers ${ }^{9} \cdot$ Inger B. Schipper $^{10} \cdot$ Luke P. H. Leenen $^{11} \cdot$ Mariska A. C. de Jongh $^{12}$
}

Received: 11 November 2021 / Accepted: 21 January 2022 / Published online: 8 February 2022

(c) The Author(s), under exclusive licence to Springer-Verlag GmbH Germany 2022

\begin{abstract}
Purpose The SARS-CoV-2 pandemic severely disrupted society and the health care system. In addition to epidemiological changes, little is known about the pandemic's effects on the trauma care chain. Therefore, in addition to epidemiology and aetiology, this study aims to describe the impact of the SARS-CoV-2 pandemic on prehospital times, resource use and outcome.

Methods A multicentre observational cohort study based on the Dutch Nationwide Trauma Registry was performed. Characteristics, resource usage, and outcomes of trauma patients treated at all trauma-receiving hospitals during the first (W1, March 12 through May 11) and second waves (W2, May 12 through September 23), as well as the interbellum period in between (INT, September 23 through December 31), were compared with those treated from the same periods in 2018 and 2019. Results The trauma caseload was reduced by $20 \%$ during the $\mathrm{W} 1$ period and $11 \%$ during the W2 period. The median length of stay was significantly shortened for hip fracture and major trauma patients (ISS $\geq 16$ ). A $33 \%$ and $66 \%$ increase in the prevalence of minor self-harm-related injuries was recorded during the W1 and W2 periods, respectively, and a 36\% increase in violence-related injuries was recorded during the INT. Mortality was significantly higher in the W1 (2.9\% vs. $2.2 \%)$ and W2 (3.2\% vs. $2.7 \%)$ periods.

Conclusion The imposed restrictions in response to the SARS-CoV-2 pandemic led to diminished numbers of acute trauma admissions in the Netherlands. The long-lasting pressing demand for resources, including ICU services, has negatively affected trauma care. Further caution is warranted regarding the increased incidence of injuries related to violence and self-harm.
\end{abstract}

Keywords SARS-CoV-2 $\cdot$ Impact $\cdot$ Trauma $\cdot$ Pandemic $\cdot$ Outcome

\section{Introduction}

The first SARS-CoV-2 case in the Netherlands was reported on February 27, and on March 12, the Dutch government declared a national lockdown. The Dutch National Coordination Center for Patient Distribution (LCPS) was quickly instated to facilitate the transfer of SARS-CoV-2 infected patients across the Netherlands. With the national dispersion of SARS-CoV-2 infected patients, the LCPS sought to avoid a locoregional surge of capacity and minimize the impact on acute and elective non-COVID-19 care in more severely

Mitchell L. S. Driessen

mls.driessen@lnaz.nl

Extended author information available on the last page of the article affected regions. Relatively quick virus containment was realized, and most measures were revoked by the second week of May; consequently, LCPS scaled down its operations. However, due to increasing numbers of SARS-CoV-2 infections, reinstatement of (lockdown) restrictions and reactivation of LCPS were required by the end of September, without signs of relief at the end of the year.

During these 2020 outbreak periods, two main circumstances might have impacted the trauma population and provided care. First, the lockdown policies that were set to mitigate the propagation of the virus could have shifted the epidemiological characteristics of hospitalized trauma patients. Previous studies have shown widespread epidemiological and aetiological changes in trauma care [1], lateonset presentation of common medical conditions [2, 3], 
and higher surgical morbidity in patients with a concomitant SARS-CoV-2 infection [4]. Second, SARS-CoV-2 drastically changed the demand for health care services, resulting in a redistribution of material and personnel $[5,6]$. This also impacted (clinical) outcomes of patients. Previous research suggested that due to a shortage of ICU beds, a specific group of patients was less likely to be admitted to the ICU for observation, which has impacted outcomes [7].

The currently available international literature mostly concerns single centre studies with small sample sizes that cover the first infectious outbreak [8-16]. A comprehensive national study that evaluates the changes in trauma epidemiology and care for the trauma population in its entirety over multiple outbreaks is lacking. Such a study can offer valuable information on how to manage the continuity of trauma care during future pandemics or other extreme conditions.

This study aims to better understand how the SARSCoV-2 pandemic, with subsequent public health care and other societal constraints, has epidemiologically impacted trauma patient characteristics, prehospital times, resource use, trauma care and outcomes on a national scale.

\section{Methods}

\section{Setting}

The study was performed according to STROBE guidelines for observational studies [18]. We performed a nationwide, multicentre, retrospective observational cohort study. Patient characteristics, trauma aetiology, ICU resource use and clinical outcomes of trauma patients were compared.

The Netherlands encloses approximately $41,500 \mathrm{~km}^{2}$, has approximately 17.4 million inhabitants, and approximately 71,623 people were admitted into the hospital as trauma patients in 2020 . All acutely admitted trauma patients registered between weeks 2 and 52 of 2018, 2019 and 2020 were included. LCPS was established on March 12 and scaled down its operations gradually to a surveillance level by May 11. This period marks the first wave of SARS-CoV-2 infections in the Netherlands and will be referred to as Wave 1 (W1). By September 23, the LCPS was reinstated due to a second wave of SARS-CoV-2 infections throughout the Netherlands. This period was marked until December 31 and will be referred to as Wave 2 (W2). The period in which the LCPS acted on a surveillance level is referred to as the interbellum (INT).

To account for seasonal influences on trauma patients' characteristics and aetiology, the reference periods for the first wave (RW1), the second wave (RW2) and the interbellum (RINT) were established based on the same period in 2018-2019 combined. The main outcomes were measured as in-hospital mortality and 30-day (30 D) mortality.

\section{Data collection}

Data were extracted from the Dutch National Trauma Registry (DNTR) [19]. The DNTR prospectively documents all injured patients who were directly admitted to a hospital through the emergency department (ED) within $48 \mathrm{~h}$ after trauma, regardless of their age, injury location, and severity. Patients without vital signs upon arrival at the ED were excluded. Moreover, patients transferred within $48 \mathrm{~h}$ after the incident are likely to be registered twice. Therefore, those transferred to another hospital after ED treatment were excluded. ${ }^{18}$ The DNTR dataset includes the Utstein template items for uniform reporting of data following major trauma and covers $100 \%$ of the trauma-receiving hospitals in the Netherlands [19]. Injuries are coded by trained data registrars according to the Abbreviated Injury Scale (AIS) 2005 update 2008 [20].

\section{Populations}

Subgroup analyses were performed for (1) patients with minor injuries defined as injuries with an injury severity score (ISS) [21] of 8 or less, (2) patients who sustained a hip fracture and had an ISS $\leq 15$ and (3) major trauma (MT) patients, which were defined as having an ISS of 16 and higher.

\section{Transport times}

Differences in prehospital trauma care were assessed based on median prehospital transport times and the number of actual dispatches of Dutch mobile medical teams (MMTs) to provide prehospital on-scene medical assistance for severely injured patients [22]. Ambulance dispatches were categorized in four time intervals: response time (a) was defined as the time required for emergency medical services (EMS) to arrive at the scene of an accident; on-scene time (b) was defined as the time spent on scene by EMS professionals; transport time (c) was defined as the time from departing the scene to arrival at the hospital; total prehospital time (d) was defined as the total time between an emergency call and arrival at the hospital.

\section{Statistical analysis}

Categorical data are described as numbers (percentages) and were compared using a chi-squared test. Continuous data are expressed as the mean (standard deviation (SD)) or median (interquartile range, IQR, 25th-75th percentile) for normally or non-normally distributed variables, respectively, and were compared using a $t$ test or a Wilcoxon-Mann-Whitney test, 
as appropriate. A $p$ value of $<0.05$ was considered significant. Valid percentages were used, excluding missing values. The number of missing values per variable is listed in Supplemental Material Table 1.
The number of patients registered each week in 2020 was recorded as the observed $(\mathrm{O})$ volume. The average number of patients registered each week in 2018 and 2019 was recorded as the expected (E) volume. Thereafter, the $\mathrm{O}$ was

Table 1 Patient characteristics of those admitted during the first and second SARS-CoV-2 waves, the interbellum period, and their respective reference periods from 2018 and 2019

\begin{tabular}{|c|c|c|c|c|c|c|}
\hline & \multicolumn{3}{|l|}{2020} & \multicolumn{3}{|l|}{$2018 / 2019$} \\
\hline & Wave $1(\mathrm{~W} 1) N(\%)$ & $\begin{array}{l}\text { Interbellum (INT) } \\
N(\%)\end{array}$ & Wave 2 (W2) N (\%) & $\begin{array}{l}\text { Reference Wave } \\
1 \text { (RW1) } N(\%)\end{array}$ & $\begin{array}{l}\text { Reference Inter- } \\
\text { bellum (RINT) } \\
N(\%)\end{array}$ & $\begin{array}{l}\text { Reference } \\
\text { Wave } 2 \text { (RW2) } \\
N(\%)\end{array}$ \\
\hline Total included, $n$ & 12,184 & 25,506 & 17,455 & 30,430 & 51,196 & 39,165 \\
\hline Weekly admissions, $n$ & 1523 & 1342 & 1247 & 1902 & 1347 & 1399 \\
\hline Male gender, $n(\%)$ & $6097(50.0)$ & $13,015(51.0)$ & $8402(48.1)$ & $15,274(50.2)$ & $25,753(50.3)$ & $20,165(48.5)$ \\
\hline \multicolumn{7}{|l|}{ Median age (IQR) } \\
\hline Overall & $67(34-81)^{*}$ & $63(27-80)$ & $69(35-83)^{\ddagger}$ & $63(27-81)$ & $63(27-80)$ & $67(33-82)$ \\
\hline Minor injury & $50(10-74)$ & $46(12-73)$ & $51(13-76)^{\ddagger}$ & $47(12-73)$ & $47(12-73)$ & $51(16-76)$ \\
\hline Hip fracture & $81(72-87)$ & $80(72-87)^{\S}$ & $81(73-88)$ & $81(72-87)$ & $81(72-87)$ & $81(72-88)$ \\
\hline ISS $\geq 16$ & $58(36-74)$ & $57(34-74)$ & $61(37-76)$ & $58(35-75)$ & $58(34-74)$ & $59(36-75)$ \\
\hline Median ISS (IQR) & $3(2-6)^{*}$ & $3(2-7.75)^{\S}$ & $3(2-7)^{\ddagger}$ & $3(2-8)$ & $3(2-7)$ & $3(2-8)$ \\
\hline Blunt trauma, $n(\%)$ & $10,994(95.8)^{*}$ & $23,023(96.1)^{\S}$ & $15,593(96.8)$ & $27,931(97.0)$ & $46,620(96.7)$ & $35,679(97.0)$ \\
\hline Minor injuries, $n(\%)$ & $6140(50.4)^{*}$ & $13,856(54.3)^{\S}$ & $8797(50.4)^{\ddagger}$ & $17,396(57.2)$ & $28,875(56.4)$ & $21,384(54.6)$ \\
\hline Hip fracture, $n(\%)$ & $3183(26.7)^{*}$ & $5677(22.6)^{\S}$ & $4645(27.1)^{\ddagger}$ & $6801(22.4)$ & $11,116(21.8)$ & $9380(24.1)$ \\
\hline \multicolumn{7}{|l|}{ ISS $\geq 16$} \\
\hline Number, $n(\%)$ & $739(6.1)^{*}$ & $1599(6.3)^{\S}$ & $1037(5.9)^{\ddagger}$ & $1704(5.6)$ & $3074(6.0)$ & $2237(5.7)$ \\
\hline $\begin{array}{l}\text { ICU admission, } n \\
\quad(\%)\end{array}$ & $342(46.3)^{*}$ & 894 (55.9) & $513(49.5)$ & 918 (53.9) & $1706(55.5)$ & $1189(53.1)$ \\
\hline $\begin{array}{l}\text { Median ICU LOS } \\
\text { (IQR) }\end{array}$ & $3(2-6)$ & $3(2-7.75)$ & $3(2-7)^{\ddagger}$ & $3(2-8)$ & $3(1-7)$ & $3(2-8)$ \\
\hline $\begin{array}{l}\text { Respiratory sup- } \\
\text { port, } n(\%)\end{array}$ & $175(58.9)^{*}$ & $413(52.9)^{\S}$ & $255(56.4)^{\ddagger}$ & $342(43.4)$ & $662(45.6)$ & 499 (47.4) \\
\hline \multicolumn{7}{|l|}{$\begin{array}{l}\text { Median hospital LOS } \\
\text { (IQR) }\end{array}$} \\
\hline Overall & $4(2-7)$ & $3(2-7)^{\S}$ & $4(2-8)$ & $3(2-7)$ & $3(2-7)$ & $4(2-8)$ \\
\hline Minor injury & $2(2-4)$ & $2(2-4)^{\S}$ & $2(2-4)^{\ddagger}$ & $2(2-4)$ & $2(2-4)$ & $2(2-4)$ \\
\hline Hip fracture & $6(5-9)^{*}$ & $6(5-9)^{\S}$ & $7(5-10)^{\ddagger}$ & $7(5-10)$ & $7(5-10)$ & $7(5-10)$ \\
\hline ISS $\geq 16$ & $6(4-9)^{*}$ & $7(3-14)^{\S}$ & $6(4-9)^{\ddagger}$ & $5(3-9)$ & $7(3-15)$ & $5(4-9)$ \\
\hline \multicolumn{7}{|l|}{ Mortality, $n(\%)$} \\
\hline Overall & $357(2.9)^{*}$ & $582(2.3)$ & $560(3.2)^{\ddagger}$ & $692(2.2)$ & $1165(2.3)$ & $1053(2.7)$ \\
\hline Minor injury & $63(1.0)^{*}$ & $69(0.5)^{\S}$ & $85(1.0)$ & $119(0.7)$ & $196(0.7)$ & $183(0.8)$ \\
\hline Hip fracture & $111(3.5)$ & $151(2.7)$ & $171(3.7)$ & $199(2.9)$ & $304(2.7)$ & $313(3.3)$ \\
\hline ISS $\geq 16$ & $132(17.9)$ & $282(17.6)$ & $215(20.7)^{\ddagger}$ & $290(17.0)$ & $488(15.9)$ & $393(17.6)$ \\
\hline \multicolumn{7}{|l|}{$\begin{array}{l}\text { 30-Day mortality, } \\
n(\%)\end{array}$} \\
\hline Overall & $574(4.7)^{*}$ & $929(3.6)$ & $908(5.2)^{\ddagger}$ & $1090(3.6)$ & $1778(3.5)$ & $1650(4.2)$ \\
\hline Minor injury & $116(1.9)^{*}$ & $164(1.2)$ & $173(2.0)^{\ddagger}$ & $226(1.3)$ & $344(1.2)$ & $369(1.7)$ \\
\hline Hip fracture & $216(6.8)^{*}$ & $330(5.8)$ & $353(7.6)^{\ddagger}$ & $402(5.9)$ & $639(5.7)$ & $606(6.4))$ \\
\hline ISS $\geq 16$ & $154(20.8)$ & $309(19.3)$ & $239(23.0)^{\ddagger}$ & $312(18.3)$ & $546(17.8)$ & $428(19.1)$ \\
\hline
\end{tabular}

ISS Injury Severity Score, LOS length of stay

*1st Wave (W1) differs significantly ( $p$ value <0.05) from its reference period (RW1) in 2018 and 2019 combined

${ }^{\S}$ Interbellum period (INT) differs significantly $(p$ value $<0.05)$ from its reference period (RINT) in 2018 and 2019 combined

${ }^{\ddagger}$ 2nd Wave (W2) differs significantly $(p$ value $<0.05$ ) from its reference period (RW2) in 2018 and 2019 combined 
divided by the $\mathrm{E}$ computing the $\mathrm{O} / \mathrm{E}$ ratio. An $\mathrm{O} / \mathrm{E}$ ratio $<1$ indicates that the volume in that specific week of 2020 was lower than expected, and an $\mathrm{O} / \mathrm{E}$ ratio $>1$ indicates a higher volume than expected. Four-week rolling averages of O/E ratios were used to prevent 1-week-outlier artefacts. Statistical analyses were performed using IBM SPSS Statistics for Windows, Version 24.0. Armonk, NY: IBM Corp [23].

\section{Results}

\section{Acute trauma admissions}

In $\mathrm{W} 1$, a total of 12,184 acute trauma admissions were recorded in the DNTR (i.e., 1523 admitted trauma patients per week on average). This result resembles a decrease of $20 \%$ compared to the 30,430 acute trauma admissions during RW1 (i.e., 1902 admitted weekly on average). The decreased number of acute trauma admissions resolved during INT, with a total of 25,506 acute trauma admissions (i.e., 1342 admissions per week), compared to the 51,196 patients (i.e., 1347 admissions per week on average) during RINT. In W2, the number of acute trauma admissions dropped by $10.8 \%$, to a total of 17,455 patients (i.e., 1247 admissions per week), compared to the 39,165 patients (i.e., 1399 admissions per week on average) during RW2 (Table 1).

\section{Patient's characteristics}

During W1 and W2, the median age of trauma patients tended to be higher, with 67 years (IQR 34-81) and 69 years (IQR 35-83) compared to 63 years (IQR 27-81) and 67 years (IQR 33-82) in RW1 and RW2, respectively (Table 1). The median ISS was significantly lower during $\mathrm{W} 1$ and $\mathrm{W} 2$, with 3 (IQR 2-6) during W1 and 3 (IQR 2-7) during W2 vs. 3 (IQR 2-8) during both RW1 and RW2 $(p<0.001)$. During W1 and W2, injuries were less frequently of the blunt type $(n=10,994(95.8 \%))$ and $(n=15,593(96.8 \%)$ versus $(n=27,931(97.0 \%))$ and $(n=35,679(96.7 \%)),(p<0.001)$ (Table 1). Otherwise, there were no notable differences in patient characteristics. The weekly observed/expected ratios for patients with minor injuries, hip fractures and MT are displayed in Fig. 1.

\section{Injury cause}

Among trauma patients with ISSs of 1-15 and 16-24, the prevalence of sports-related injuries decreased by $45 \%$ and $29 \%$, respectively, during the $\mathrm{W} 1$ period (Table 2). In contrast, the prevalence of sports-related trauma patients with an ISS $>25$ increased by $21 \%$ and $22 \%$ in $\mathrm{W} 1$ and $\mathrm{W} 2$, respectively, compared to the reference periods.
During the $\mathrm{W} 1$ and $\mathrm{W} 2$ we recorded a decrease in the prevalence of injuries due to road traffic accidents (RTAs) between $27 \%$ and $29 \%, 3 \%$ and $22 \%$, and $11 \%$ and $23 \%$ in respectively the ISS $1-15,16-24$ and $\geq 25$ categories, respectively. Compared to RW1, injuries inflicted by violence decreased during $\mathrm{W} 1$ by $30 \%, 44 \%$ and $48 \%$ in the ISS 1-15, ISS 16-24 and $\geq 25$ categories, respectively. Compared to the reference period, injuries due to interpersonal violence increased during INT in all injury severity categories, ranging from a $12 \%$ increase in the ISS $\geq 25$ category to a $52 \%$ increase in the ISS 15-24 category. During W2, injuries resulting from interpersonal violence graded as an ISS between 1-15 and ISS equal to or above 25 decreased by $7 \%$ and $32 \%$, respectively, compared to RW2.

The prevalence of injuries due to self-harm increased in all 2020 periods and for every ISS category, ranging from $5 \%$ up to $9 \%$. The prevalence of self-harm related in the ISS $16-24$ category increased by $6 \%$ during the $\mathrm{W} 1$ and decreased by $36 \%$ and $21 \%$ in the INT and W2. In contrast to those decreases the prevalence of severe self-harm related injuries (ISS $\geq 25$ ) increased by $41 \%$ and $26 \%$ during the INT and W2 periods, respectively.

\section{Minor injuries}

During W1, a $29.4 \%$ (6140 vs. 17,396 ) decrease in the total number of trauma patients admitted with minor injuries (ISS $\leq 8$ ) was recorded. During INT and W2, decreases of $4 \%(13,856$ vs. 28,875$)$ and $17.7 \%$ (8797 vs. 31,284$)$, respectively, compared to the reference periods, were recorded (Table 1). Compared to the respective reference periods, the in-hospital mortality of patients with minor injuries significantly increased from $0.7 \%(n=119)$ in RW1 to $1.0 \%$ $(n=63)$ in $\mathrm{W} 1(p=0.009)$ and significantly decreased during INT $0.5 \%(n=69)$ vs. $0.7 \%(n=196)$ in RINT $(p=0.025)$. Compared to RW1, we recorded a significant decrease (20.8\%) in the frequency of patients discharged to nursing homes. Consequently, the number of patients discharged to their homes and rehabilitation centres increased by $5.7 \%$ and $3.8 \%$, respectively (Table 3 ).

\section{Hip fractures}

The total number of trauma patients admitted with a hip fracture decreased by $6.4 \%$ (3183 vs. 6801) during W1 and $1.0 \%$ (4645 vs. 9380) during W2 compared to their respective reference periods RW1 and RW2 (Table 1). A $2 \%$ (5677 vs. 11,116$)$ increase was recorded during INT. The median length of stay for hip fracture patients was significantly shortened during all periods in 2020, with 6 days (IQR 5-9) during W1 and INT and 7 days (IQR $5-10)$ during W2 $(p=<0.001)$ (Table 1). The in-hospital mortality of patients admitted after sustaining a hip 
Fig. 1 The weekly O/E observed (in 2020) versus expected (average 2018-2019) trauma patient ratios for those admitted after sustaining a minor injury (ISS $\leq 8$ ), a hip fracture or a major trauma (ISS $\geq 16$ ) and the four-week rolling averages of the $\mathrm{O} / \mathrm{E}$ ratios (dashed line)
Minor injuries

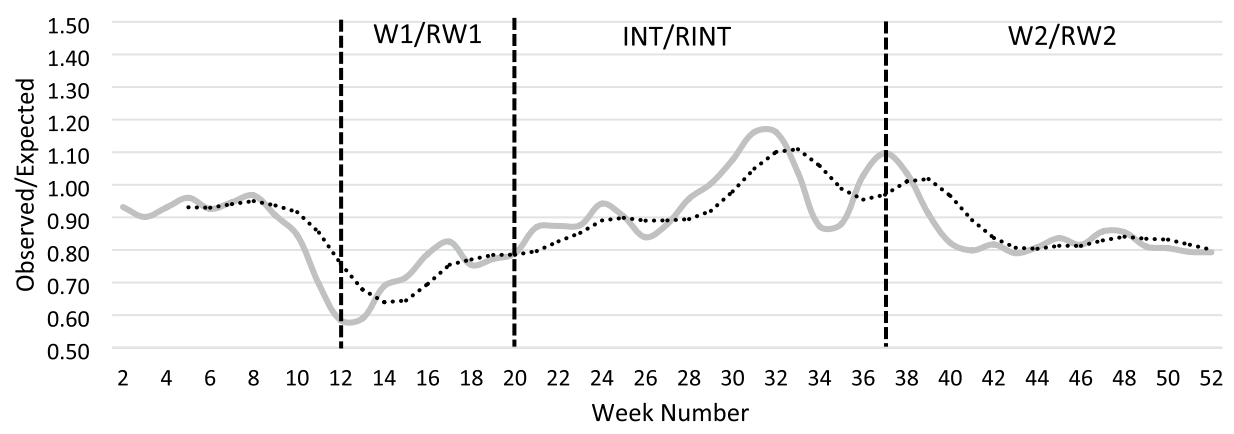

Hip fractures

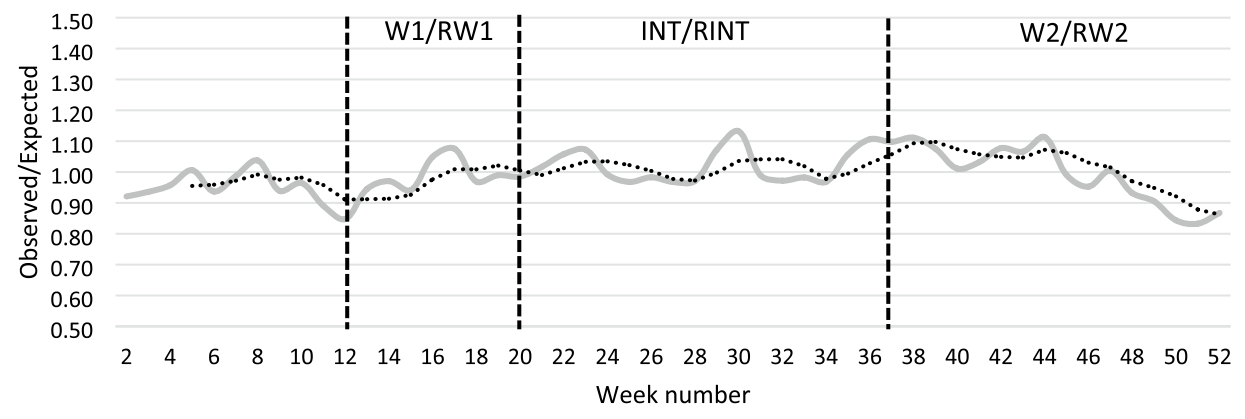

Major Trauma

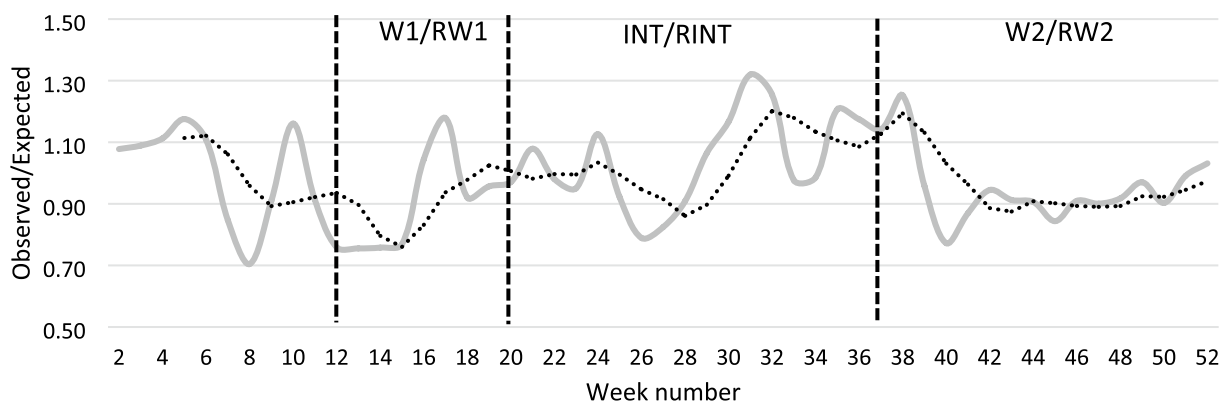

fracture was similar during the W1, INT and W2 compared to the respective reference periods. However, the 30-day mortality increased significantly during both SARS-CoV-2 periods, namely, $6.8 \%(n=216)$ vs. $5.9 \%(n=402)$ during $\mathrm{W} 1(p=0.009)$ and $7.6 \%(n=353)$ vs. $6.4 \%(n=606)$ during W2 $(p=<0.001)$. Compared to the respective reference periods, hip fracture patients were $11.6 \%, 12.8 \%$ and $6.2 \%$ less frequently discharged to nursing homes during W1, INT and W2 (Table 3). Moreover, the number of hip fracture patients discharged to their own homes increased by $26.7 \%$ in $\mathrm{W} 1,4.0 \%$ in INT, and $7.1 \%$ in $\mathrm{W} 2$ compared to the respective reference periods.

\section{Major trauma patients}

Compared to the reference periods, a $13.3 \%$ (739 vs. 1704 ) and a $7.3 \%$ (1037 vs. 2237) decrease in MT patients was recorded during $\mathrm{W} 1$ and W2. In contrast, there was a 4\% (1599 vs. 3074) increase in MT patients who were admitted throughout INT (Table 1). Hospital length of stay (LOS) was lengthened during both waves, with a median duration of 6 days (IQR 4-9) compared to 5 days (IQR 3-9) and 5 days (IQR 4-9) in the reference periods. ICU admission decreased for MT patients. During $\mathrm{W} 1,46.3 \%(n=342)$ of MT patients were admitted to 
Table 2 Trauma causes per injury severity subgroup, for those admitted during the first and second SARS-CoV-2 waves, the interbellum period and during their respective reference periods from 2018 and 2019

\begin{tabular}{|c|c|c|c|c|c|c|}
\hline & \multicolumn{3}{|l|}{2020} & \multicolumn{3}{|l|}{$2018 / 2019$} \\
\hline & Wave $1(\mathrm{~W} 1) N(\%)$ & Interbellum (INT) $N(\%)$ & Wave 2 (W2) $N(\%)$ & $\begin{array}{l}\text { Reference } \\
\text { Wave } 1 \text { (RW1) } \\
N(\%)\end{array}$ & $\begin{array}{l}\text { Reference Inter- } \\
\text { bellum (RINT) } \\
N(\%)\end{array}$ & $\begin{array}{l}\text { Reference } \\
\text { Wave } 2 \text { (RW2) } \\
N(\%)\end{array}$ \\
\hline \multicolumn{7}{|l|}{ ISS $1-15$} \\
\hline Sports & $509(4.7)$ & $1411(6.3)$ & $852(5.6)$ & $1835(6.8 \%)$ & $2583(5.8)$ & $1991(5.8)$ \\
\hline RTA & $1990(20.3)$ & $4942(22.2)$ & $2481(16.4)$ & $5614(21.0)$ & $10,361(23.2)$ & $6844(20.2)$ \\
\hline Home and leisure & $7594(70.9)$ & $14,620(65.3)$ & $10,958(72.5)$ & $17,787(66.5)$ & $29,140(65.3)$ & $23,292(68.3)$ \\
\hline Work & $352(3.3)$ & $583(2.6)$ & $483(3.2)$ & $814(3.0)$ & $1359(3.0)$ & $1085(3.2)$ \\
\hline Violence & $181(1.7)$ & $498(2.2)$ & $235(1.6)$ & $519(1.9)$ & $892(2.0)$ & $693(2.0)$ \\
\hline Self-harm & $86(0.8)$ & $159(0.7)$ & $109(1.0)$ & $164(0.6)$ & $293(0.7)$ & $206(0.6)$ \\
\hline \multicolumn{7}{|l|}{ ISS 16-24 } \\
\hline Sports & $25(5.5)$ & 69 (7.6) & $32(5.5)$ & $70(7.1)$ & $114(6.6)$ & $65(5.1)$ \\
\hline RTA & $194(42.6)$ & $400(44.3)$ & $211(36.5)$ & $401(40.8)$ & 779 (45.6) & $542(42.5)$ \\
\hline Home and leisure & $178(39.1)$ & $334(37.0)$ & $271(46.9)$ & $381(38.8)$ & $636(37.2)$ & $530(41.5)$ \\
\hline Work & $30(6.6)$ & $41(4.5)$ & $30(5.2)$ & $62(6.3)$ & $71(4.2)$ & $61(4.8)$ \\
\hline Violence & $9(2.0)$ & $41(4.5)$ & $21(3.6)$ & $32(3.3)$ & $54(3.2)$ & $45(3.5)$ \\
\hline Self-harm & $19(4.2)$ & $18(2.0)$ & $13(2.2)$ & $36(3.7)$ & $56(3.3)$ & $33(2.6)$ \\
\hline \multicolumn{7}{|l|}{ ISS $25-70$} \\
\hline Sports & $13(4.7)$ & $28(4.1)$ & $20(4.5)$ & $27(4.1)$ & $46(3.8)$ & $30(3.4)$ \\
\hline RTA & $105(38.0)$ & $293(43.7)$ & $152(34.6)$ & $271(41.9)$ & $515(43.1)$ & $343(39.2)$ \\
\hline Home and leisure & $121(43.8)$ & $228(34.0)$ & $191(43.5)$ & $252(38.9)$ & 445 (37.2) & $358(41.0)$ \\
\hline Work & $10(3.6)$ & $40(6.0)$ & $18(4.1)$ & $30(4.6)$ & $65(5.4)$ & $41(4.7)$ \\
\hline Violence & $6(2.2)$ & $30(4.5)$ & $15(3.4)$ & $23(3.6)$ & $50(4.2)$ & $34(3.9)$ \\
\hline Self-harm & $21(7.6)$ & $52(7.7)$ & $43(9.8)$ & $44(6.8)$ & $74(6.2)$ & $68(7.8)$ \\
\hline
\end{tabular}

ISS Injury Severity Score, RTA road traffic accident

Table 3 Discharge destination for those who endured minor injuries, hip fractures and major trauma and were admitted during the first and second SARS-CoV-2 waves, the interbellum period, and their respective reference periods from 2018 and 2019

\begin{tabular}{|c|c|c|c|c|c|c|}
\hline & \multicolumn{3}{|l|}{2020} & \multicolumn{3}{|l|}{$2018 / 2019$} \\
\hline & Wave $1(\mathrm{~W} 1) N(\%)$ & $\begin{array}{l}\text { Interbellum (INT) } \\
N(\%)\end{array}$ & Wave 2 (W2) $N(\%)$ & $\begin{array}{l}\text { Reference Wave } \\
1 \text { (RW1) } N(\%)\end{array}$ & $\begin{array}{l}\text { Reference Inter- } \\
\text { bellum (RINT) } \\
N(\%)\end{array}$ & $\begin{array}{l}\text { Reference } \\
\text { Wave } 2 \text { (RW2) } \\
N(\%)\end{array}$ \\
\hline \multicolumn{7}{|l|}{ Minor injury } \\
\hline Own home & $5047(83.0)$ & 11,246 (81.6) & 6876 (78.9) & $13,662(78.5)$ & $22,894(79.8)$ & $16,396(76.7)$ \\
\hline Nursing home & $237(3.8)$ & $560(4.1)$ & $440(5.0)$ & $833(4.8)$ & $1241(4.3)$ & $1051(4.9)$ \\
\hline $\begin{array}{l}\text { Rehabilitation } \\
\text { centre }\end{array}$ & $332(5.5)$ & $891(6.5)$ & $653(7.5)$ & $926(5.3)$ & $1423(4.9)$ & $1371(6.5)$ \\
\hline \multicolumn{7}{|l|}{ Hip fractures } \\
\hline Own home & $1339(45.1)$ & $2152(38.9)$ & $1749(39.1)$ & 2423 (35.6) & 4041 (37.4) & $3310(36.5)$ \\
\hline Nursing home & $584(19.7)$ & 1014 (18.3) & $888(19.8)$ & $1473(22.3)$ & $2272(21.0)$ & $1915(21.1)$ \\
\hline $\begin{array}{l}\text { Rehabilitation } \\
\text { centre }\end{array}$ & $910(30.6)$ & $1816(32.9)$ & $1412(31.6)$ & $1762(26.7)$ & 3018 (27.9) & $2632(29.0)$ \\
\hline \multicolumn{7}{|l|}{$\mathrm{ISS} \geq 16$} \\
\hline Own home & $319(52.5)$ & $700(53.1)$ & $433(52.7)$ & $709(50.1)$ & $1246(48.2)$ & $862(46.7)$ \\
\hline Nursing home & $25(4.1)$ & $57(4.3)$ & $44(5.4)$ & $82(5.8)$ & $162(6.3)$ & $121(6.6)$ \\
\hline $\begin{array}{l}\text { Rehabilitation } \\
\text { centre }\end{array}$ & $122(20.1)$ & $251(19.1)$ & $156(19.0)$ & $232(16.4)$ & $412(15.9)$ & $333(18.1)$ \\
\hline
\end{tabular}

ISS Injury Severity Score 
the ICU, and $49.5 \%(n=513)$ were admitted during W2, compared to $53.9 \%(n=918)$ and $53.1 \%(n=1189)$ in the respective reference periods. Moreover, ICU length of stay (ICU LOS) was shortened. Compared to a median ICU LOS of 3 days (IQR 2-8) in all reference periods, we recorded a median ICU LOS of 3 days (IQR 2-6) and 3 days (IQR 2-7) during W1 and W2, respectively. Compared to the respective reference periods, the percentage of ICU-admitted MT patients who received respiratory support increased by $15.5 \%$ during $\mathrm{W} 1,7.3 \%$ during INT, and 9\% during W2. Although MT patient in-hospital mortality was higher for all 2020 periods, a significant difference was only found during W2. In-hospital mortality increased $3.1 \%(p=0.031)$, and 30D mortality increased $3.9 \%(p=0.001)$ compared to RW2 (Table 1). Compared to the respective reference periods, MT patients were $29.3 \%, 31.7 \%$ and $18.2 \%$ less frequently discharged to nursing homes during W1, INT and W2 (Table 3). Moreover, the number of patients discharged to their own homes increased by $4.7 \%$ in W1, $10.2 \%$ in INT, and $12.8 \%$ in W2 compared to the respective reference periods.

\section{Transport times}

The majority of patients were transported by ambulance, and this proportion significantly increased to $78.3 \%$ during both W1 and W2 (Table 4). In comparison to the reference periods, mobile medical teams (MMTs) were significantly less frequently dispatched during all 2020 periods. In contrast, transport by EMS increased during these periods. The response time was significantly different during both INT and W2, with a median of 9 min (IQR 6-13) compared to 9 min (IQR 6-12). Furthermore, the median on-scene time significantly increased during W1 (20 min (IQR 14-27)) vs. (19 $\min$ (IQR 14-26)), INT (20 $\min$ (IQR 14-26)) vs. (19 min (IQR 14-25)) and W2 (21 min (IQR 15-28)) vs. (20 min (IQR 15-26)). Compared to the historical data, the transport time was only lengthened during W2 (18 min (IQR $12-25)$ ) vs. (17 min (IQR 1224)). Consequently, the total prehospital time was significantly longer for all periods in 2020: $54 \mathrm{~min}$ (IQR 44-65) during W1, $53 \mathrm{~min}$ (IQR 43-64) during INT, and 54 min (IQR 45-66) during W2. The total emergency room treatment time was significantly shorter during W1 (163 min (IQR 115-220)) vs. (171 min (IQR 122-232)) and INT (167 min (IQR 118-225)) vs. (173 min (IQR 123-234)).

Table 4 Transport measures and median transport times for those admitted during the first and second SARS-CoV-2 waves, the interbellum period, and their respective reference periods from 2018 and 2019

\begin{tabular}{|c|c|c|c|c|c|c|}
\hline & \multicolumn{3}{|l|}{2020} & \multicolumn{3}{|l|}{$2018 / 2019$} \\
\hline & Wave 1 (W1) $N(\%)$ & $\begin{array}{l}\text { Interbellum (INT) } \\
N(\%)\end{array}$ & Wave 2 (W2) $N(\%)$ & $\begin{array}{l}\text { Reference Wave } \\
1 \text { (RW1) } N(\%)\end{array}$ & $\begin{array}{l}\text { Reference Inter- } \\
\text { bellum (RINT) } \\
N(\%)\end{array}$ & $\begin{array}{l}\text { Reference } \\
\text { Wave } 2 \text { (RW2) } \\
N(\%)\end{array}$ \\
\hline $\begin{array}{l}\text { MMT at the scene } \\
\text { for major trauma } \\
\text { patients }(\%)\end{array}$ & $152(20.8)^{*}$ & $332(20.9)^{\S}$ & $205(19.9)^{\ddagger}$ & $416(25.0)$ & $735(24.5)$ & $510(23.3)$ \\
\hline $\begin{array}{l}\text { Major trauma patients } \\
\text { directly transported } \\
\text { to MTC }\end{array}$ & 509 (68.9) & $1106(69.2)$ & $699(67.4)$ & $1195(70.0)$ & $2060(67.0)$ & $1483(66.3)$ \\
\hline $\begin{array}{l}\text { Ambulance transpor- } \\
\text { tation }(\%)\end{array}$ & $9011(78.3)^{*}$ & $18,360(75.5)$ & $13,147(78.3)^{\neq}$ & $21,427(73.4)$ & $36,607(74.3)$ & $28,668(76.2)$ \\
\hline $\begin{array}{l}\text { Median response time } \\
\text { (IQR) }\end{array}$ & $9(6-12)$ & $9(6-13)^{\S}$ & $9(6-13)^{\ddagger}$ & $9(6-12)$ & $9(6-12)$ & $9(6-12)$ \\
\hline $\begin{array}{l}\text { Median transport } \\
\text { time (IQR) }\end{array}$ & $18(12-24)$ & $18(12-25)$ & $18(12-25)^{\ddagger}$ & $18(12-25)$ & $18(12-25)$ & $17(12-24)$ \\
\hline $\begin{array}{l}\text { Median on scene time } \\
\text { (IQR) }\end{array}$ & $20(14-27)^{*}$ & $20(14-26)^{\S}$ & $21(15-28)^{\ddagger}$ & $19(14-26)$ & $19(14-25)$ & $20(15-26)$ \\
\hline $\begin{array}{l}\text { Median total pre- } \\
\text { hospital time (IQR) }\end{array}$ & $54(44-65)^{*}$ & $53(43-64)^{\S}$ & $54(45-66)^{\ddagger}$ & $51(41-63)$ & $51(41-63)$ & $52(42-64)$ \\
\hline $\begin{array}{l}\text { Median total time of } \\
\text { ER treatment (IQR) }\end{array}$ & $163(115-220)^{*}$ & $167(118-225)^{\S}$ & $174(125-233)$ & $171(122-232)$ & $173(123-234)$ & $174(124-234)$ \\
\hline
\end{tabular}

$M M T$ mobile medical team, MTC major trauma centre, ER emergency room

*Wave 1 (W1) differs significantly ( $p$ value $<0.05$ ) from its reference period (RW1) in 2018 and 2019 combined

${ }^{\S}$ Interbellum period (INT) differs significantly $(p$ value $<0.05)$ from its reference period (RINT) in 2018 and 2019 combined

${ }^{\ddagger}$ Wave 2 (W2) differs significantly $(p$ value $<0.05$ ) from its reference period (RW2) in 2018 and 2019 combined 


\section{Discussion}

We demonstrated that SARS-CoV-2-induced social restrictions have impacted the number and epidemiological characteristics of the hospitalized trauma population. Moreover, the pandemic has led to organizational changes and medical resource shortages that have impacted the entire acute trauma care chain, potentially affecting patient outcomes. In this national study, we made the following observations that should be considered in preparation for future pandemic peaks.

\section{Trauma aetiology}

Staying at home is perceived to reduce the risk of becoming injured, as individuals may otherwise be exposed to potentially unsafe traffic and working situations or run the risk of interpersonal violence. Not surprisingly, compared to years prior to the SARS-CoV-2 pandemic, the number of acute trauma admissions was reduced by approximately $20 \%$ during the first and 11\% during the second infectious wave in the Netherlands. However, this apparent reduction in trauma caseload was counterbalanced by a steady flow of elderly admitted with hip fractures and MT patients [8,24-26]. The restrictions reduced the number of injuries due to sports; however, they did not prevent people from becoming seriously injured or from falling at home.

Another development of interest was the increase in the incidence of penetrating trauma. No specific analysis was performed in this study; however, penetrating injuries are most commonly a result of person-to-person violence outside of their own home or related to self-harm [27]. Multiple SARS-CoV-2-related stressors, such as isolation, quarantine, fear and uncertainty, economic fallout, social abuse or violence, might have resulted in increased vulnerability to automutilation and suicidal behaviour [28]. Therefore, the $41 \%$ and $26 \%$ increase frequency of minor (ISS $\leq 15$ ) self-harm-related injuries during the respective first and second waves and the $37 \%$ increase in violencerelated severe injuries (ISS $\geq 16$ ) during the interbellum are worrisome. Unfortunately, we are not the first to report this, and increased numbers of injuries resulting from self-harm during the periods of lockdown were found in France [10, 11], the UK [12, 13], Australia [14, $15]$ and the US [16, 17]. Preparing for indefinite periods of social restrictions that may lie ahead, policy-makers might want to take precautionary measures to identify and protect those that pose the highest risk of self-harm or domestic abuse and consider additional funding towards mental health services to meet demand.

\section{Trauma care}

The unprecedented strain of the SARS-CoV-2 pandemic has impacted the health care system in various ways, with a detrimental impact on trauma care. The number of elderly patients with hip fractures has remained consistent with the pre-SARS-CoV-2 era; however, an increase in mortality was found for the hip fracture population. This increase could be attributed to multiple factors. First, these patients were particularly more vulnerable during the SARS-CoV-2 pandemic. Both older age and comorbidities are triggers for an increased risk of infection or mortality caused by SARSCoV-2 $[29,30]$. The literature reports an in-hospital mortality rate of approximately $30 \%$ for hip fracture patients with a concomitant SARS-CoV-2 infection [4]. Second, there is compelling evidence that early surgery, prompt orthogeriatric care and early postoperative ambulation improve outcomes for patients with hip fractures [31, 32]. Our results illustrate that an accelerated care pathway was adopted to shorten the length of hospital stay. However, shortening of hospital length of stay may have led to a suboptimal or unsafe level of recovery before discharge. Third, nursing homes and rehabilitation centres were inadequately prepared to protect their health care workers and patients from infecting each other with SARS-CoV-2. During the first wave, the latter was the case in the Netherlands, as the scarcity of appropriate protective equipment allegedly caused several local outbreaks in nursing homes. The decreased number of patients discharged to nursing homes suggests a response to suboptimal conditions. However, further study is needed to investigate whether these elements have led to unfavourable outcomes for trauma patients admitted after a sustained hip fracture.

Similar to patients with a hip fracture, the number of MT patients has remained substantial, demonstrating the necessity to retain fully functional trauma teams, operating rooms, and especially the availability of ICU beds when planning for future epidemics. Severely injured patients highly rely on the availability of emergency services and immediate access to specialized care, including ICUs. The pressing demand on ICU facilities during the first infectious peak has had a detrimental impact on patients with minor to moderate traumatic brain injuries [7]. Patients without an obvious ICU indication (e.g., forced by conditions such as prehospital intubation or with a low Glasgow Coma Score) were denied access to the ICU and instead were closely monitored so that any deterioration could be quickly identified, which might have led to more favourable outcomes.

\section{Prehospital care}

The SARS-CoV-2 pandemic has affected emergency medical services in different ways. Social distancing and working 
from home resulted in fewer people on the roads, leading to shortened total EMS prehospital times. However, the increased demand induced by the SARS-CoV-2 pandemic and the subsequent mandatory infection prevention measures could elongate the total EMS prehospital time. A study from the US did not find differences in total prehospital time during the SARS-CoV-2 pandemic compared to 2019, even though transport time was significantly shorter during the pandemic [33]. Among the Dutch trauma population, the prehospital EMS times were significantly longer in all 2020 time periods. An increased on-scene time was the main cause of the elongated total prehospital time. This increase, in turn, could be a potential cause of the recorded increased mortality because there is compelling evidence that a longer on-scene time is associated with increased mortality [34]. More specifically, an on-scene time greater than 20 min increases the relative risk of mortality within 24 h by 1.797 (1.406-2.296) compared to those with an onscene time of less than $20 \mathrm{~min}$ [34]. However, the changes in transportation times found in this study are not indisputable. First, the reported association of increased on-scene times with mortality originates from the trauma population with an ISS of 9 and higher. Second, in approximately $40 \%$ of the cases included in our study, prehospital transport times were missing.

\section{Strengths and limitations}

National coverage is markedly important when evaluating trauma care during a pandemic. In contrast to other regional or single centre studies [10,12-17], this study included all trauma patients admitted to a trauma-receiving hospital in the Netherlands, regardless of the type or severity of the injury. Another major strength is that this study demonstrates trends in trauma care and effects on outcome during multiple phases of the SARS-CoV-2 pandemic and compares it with historical data prior to the SARS-CoV-2 pandemic. This study also has limitations. A coinciding SARS-CoV-2 infection is likely to negatively affect outcomes after trauma. Unfortunately, the cause of death or SARS-CoV-2 infection status of trauma patients is not documented in the DNTR. Another limitation is missing data, as shown in the supplemental materials.

\section{Conclusion}

Imposed restrictions of individuals' movements and activities in response to the SARS-CoV-2 pandemic led to fewer acute trauma admissions in the Netherlands. We observed that the trauma population was older on average and more frequently concerned with penetrating injuries, and the duration of hospital admission was shortened for vulnerable subgroups. The long-lasting pressing demand for resources, including ICU services, has negatively affected trauma care. Further caution is warranted regarding the increased incidence of injuries related to violence and self-harm.

Supplementary Information The online version contains supplementary material available at https://doi.org/10.1007/s00068-022-01891-5.

Author contributions All authors participated in the data collection and conceived and designed the study. Interpretation of the data and writing the first draft of the paper: Driessen, van Ditshuizen, Waalwijk, van den Bunt, Leenen and de Jongh. All authors read and approved the final version. The corresponding author attests that all listed authors meet authorship criteria and that no others meeting the criteria have been omitted.

\section{Declarations}

Conflict of interest All authors declare no conflicts of interest, including financial, consultant, institutional, and other relationships that might lead to bias or conflicts of interest.

Ethics statement The study is exempted from the need for informed consent because it is not subject to the Medical Research Involving Human Subjects Act. Trauma patient registration is facilitated by Dutch law, for which patient anonymity is warranted. Patients or the public were not involved in the design, conduct, reporting, or dissemination plans of our study.

\section{References}

1. Waseem S, Nayar SK, Hull P, Carrothers A, Rawal J, Chou D, et al. The global burden of trauma during the COVID-19 pandemic: a scoping review. J Clin Orthop Trauma. 2021. https://doi. org/10.1016/j.jcot.2020.11.005.

2. Rinkel LA, Prick JCM, Slot RER, Sombroek NMA, Burggraaff J, Groot AE, et al. Impact of the COVID-19 outbreak on acute stroke care. J Neurol. 2021;268:403-8. https://doi.org/10.1007/ s00415-020-10069-1.

3. Zhao J, Li H, Kung D, Fisher M, Shen Y, Liu R. Impact of the COVID-19 epidemic on stroke care and potential solutions. Stroke. 2020;51:1996-2001. https://doi.org/10.1161/STROK EAHA.120.030225.

4. Muñoz Vives JM, Jornet-Gibert M, Cámara-Cabrera J, Esteban PL, Brunet L, Delgado-Flores L, et al. Mortality rates of patients with proximal femoral fracture in a worldwide pandemic: preliminary results of the Spanish HIP-COVID Observational Study. J Bone Joint Surg Am. 2020;102: e69. https://doi.org/10.2106/JBJS. 20.00686.

5. COVIDSurg Collaborative. Mortality and pulmonary complications in patients undergoing surgery with perioperative SARS-CoV-2 infection: an international cohort study. Lancet. 2020;396(10243):27-38. https://doi.org/10.1016/S0140-6736(20) 31182-X.

6. Randelli PS, Compagnoni R. Management of orthopaedic and traumatology patients during the Coronavirus disease (COVID19) pandemic in northern Italy. Knee Surgery Sport Traumatol Arthrosc. 2020. https://doi.org/10.1007/s00167-020-06023-3.

7. Driessen MLS, Sturms LM, Bloemers FW, ten Duis HJ, Edwards MJR, den Hartog D, Kuipers EJ, Leenhouts PA, Poeze M, Schipper IB, Spanjersberg WR, Wendt KW, de Wit RJ, MD, SWAM 
van Zutphen, MD, MAC de Jongh, LPH Leenen,. The detrimental impact of the COVID-19 pandemic on major trauma outcomes in the Netherlands: a comprehensive nationwide study. SSRN J. 2021. https://doi.org/10.2139/ssrn.3823116.

8. Nuñez JH, Sallent A, Lakhani K, Guerra-Farfan E, Vidal N, Ekhtiari S, et al. Impact of the COVID-19 pandemic on an emergency traumatology service: experience at a Tertiary Trauma Centre in Spain. Injury. 2020;51:1414-8. https://doi.org/10.1016/j.injury. 2020.05.016.

9. Zhu Y, Chen W, Xin X, Yin Y, Hu J, Lv H, et al. Epidemiologic characteristics of traumatic fractures in elderly patients during the outbreak of coronavirus disease 2019 in China. Int Orthop. 2020;44:1565-70. https://doi.org/10.1007/s00264-020-04575-0.

10. Pichard R, Kopel L, Lejeune Q, Masmoudi R, Masmejean EH. IImpact of the Corana Virus Disease 2019 lockdown on hand and upper limb emergencies: experience of a referred university trauma hand centre in Paris, France. Int Orthop. 2020. https://doi. org/10.1007/s00264-020-04654-2.

11. Crenn V, El Kinani M, Pietu G, Leteve M, Persigant M, Toanen C, Varenne Y, Goffinet N, Buffenoir K, Javaudin FME. Impact of the COVID-19 lockdown period on adult musculoskeletal injuries and surgical management: a retrospective monocentric study. Sci Rep. 2020;10:1-8.

12. Rajput K, Sud A, Rees M, Rutka O. Epidemiology of trauma presentations to a major trauma centre in the North West of England during the COVID-19 level 4 lockdown. Eur J trauma Emerg Surg Off Publ Eur Trauma Soc. 2021;47:631-6. https://doi.org/ 10.1038/s41598-020-80309-x.

13. Olding J, Zisman S, Olding C, Fan K. Penetrating trauma during a global pandemic: changing patterns in interpersonal violence, self-harm and domestic violence in the Covid-19 outbreak. Surgeon. 2021;19:e9-13.

14. Williams N, Winters J, Cooksey R. Staying home but not out of trouble: no reduction in presentations to the South Australian paediatric major trauma service despite the COVID-19 pandemic. ANZ J Surg. 2020;90:1863-4. https://doi.org/10.1111/ans.16277.

15. Jacob S, Mwagiru D, Thakur I, Moghadam A, Oh T, Hsu J. Impact of societal restrictions and lockdown on trauma admissions during the COVID-19 pandemic: a single-centre cross-sectional observational study. ANZ J Surg. 2020. https://doi.org/10.1111/ans. 16307.

16. Leichtle SW, Rodas EB, Procter L, Bennett J, Schrader R, Aboutanos MB. The influence of a statewide "Stay-at-Home" order on trauma volume and patterns at a level 1 trauma center in the united states. Injury. 2020. https://doi.org/10.1016/j.injury.2020.08.014.

17. Chiba $\mathrm{H}$, Lewis $\mathrm{M}$, Benjamin ER, Jakob DA, Liasidis P, Wong MD, et al. "Safer at home": the effect of the COVID-19 lockdown on epidemiology, resource utilization, and outcomes at a large urban trauma center. J Trauma Acute Care Surg. 2021;90:708-13. https://doi.org/10.1097/TA.0000000000003061.

18. von Elm E, Altman DG, Egger M, Pocock SJ, Gøtzsche PC, Vandenbroucke JP. The strengthening the reporting of observational studies in epidemiology (STROBE) statement: guidelines for reporting observational studies. Int J Surg England. 2014;12:1495-9. https://doi.org/10.1097/EDE.0b013e3181 577654.

19. Driessen MLS, Sturms LM, Bloemers FW, ten Duis HJ, Edwards MJR, den Hartog D, et al. The Dutch nationwide trauma registry: the value of capturing all acute trauma admissions. Injury. 2020;51(11):2553-9.
20. Gennarelli TA, Wodzin EAIS. A contemporary injury scale. Injury. 2005. https://doi.org/10.1016/j.injury.2020.08.013.

21. Baker SP, O'Neill B, Haddon W, Long WB. The injury severity score: a method for describing patients with multiple injuries and evaluating emergency care. J Trauma. 1974;14:187-96.

22. Sturms LM, Driessen MLS, van Klaveren D, Ten Duis H-J, Kommer GJ, Bloemers FW, et al. Dutch trauma system performance: are injured patients treated at the right place? Injury Netherlands. 2021;52:1688-96. https://doi.org/10.1016/j.injury.2021.05.015.

23. IBM Corp (2017) Released. IBM SPSS Statistics version 25.0. 2017

24. Zhou P, Yang X, Lou Y, Wang XG, Hu B, Zhang L, Zhang W, et al. A pneumonia outbreak associated with a new coronavirus of probable bat origin. Nature. 2020. https://doi.org/10.1038/ s41586-020-2012-7.

25. Riuttanen A, Ponkilainen V, Kuitunen I, Reito A, Sirola J, Mattila VM. Severely injured patients do not disappear in a pandemic: Incidence and characteristics of severe injuries during COVID-19 lockdown in Finland. Acta Orthop. 2021;92:249-53. https://doi. org/10.1080/17453674.2021.1881241.

26. Liu J, Mi B, Hu L, Xiong Y, Xue H, Zhou W, et al. Preventive strategy for the clinical treatment of hip fractures in the elderly during the COVID-19 outbreak: Wuhan's experience. Aging. 2020;12:7619-25. https://doi.org/10.18632/aging.103201.

27. Olding J, Olding C, Bew D, Fan K. Penetrating head \& neck trauma - Epidemiology and injury characteristics in terror-related violence, interpersonal violence and deliberate self-harm at a level 1 trauma centre. Surgeon. 2019;17:133-8. https://doi.org/ 10.1016/j.surge.2019.01.001.

28. Banerjee D, Kosagisharaf JR, Sathyanarayana Rao TS. "The dual pandemic" of suicide and COVID-19: a biopsychosocial narrative of risks and prevention. Psychiatry Res. 2021;295: 113577. https://doi.org/10.1016/j.psychres.2020.113577.

29. Keny S, Bagaria V, Chaudhary K, Dhawale A. Emergency and urgent orthopaedic surgeries in non-covid patients during the COVID 19 pandemic: perspective from India. J Orthop. 2020;20:275-9. https://doi.org/10.1016/j.jor.2020.05.012.

30. Catellani F, Coscione A, D'Ambrosi R, Usai L, Roscitano C, Fiorentino G. Treatment of proximal femoral fragility fractures in patients with COVID-19 during the SARS-CoV-2 outbreak in Northern Italy. J Bone Joint Surg Am. 2020;102: e58. https://doi. org/10.2106/JBJS.20.00617.

31. Shiga T, Wajima Z, Ohe Y. Is operative delay associated with increased mortality of hip fracture patients? Systematic review, meta-analysis, and meta-regression. Can J Anaesth. 2008;55:146-54.

32. Klestil T, Röder C, Stotter C, Winkler B, Nehrer S, Lutz M, et al. Impact of timing of surgery in elderly hip fracture patients: a systematic review and meta-analysis. Sci Rep. 2018;8:13933. https:// doi.org/10.1007/BF03016088.

33. Jarvis S, Salottolo K, Berg GM, Carrick M, Caiafa R, Hamilton D, et al. Examining emergency medical services' prehospital transport times for trauma patients during COVID-19. Am J Emerg Med. 2021;44:33-7. https://doi.org/10.1016/j.ajem.2021.01.091.

34. Waalwijk JF, van der Sluijs R, Lokerman RD, Fiddelers AAA, Hietbrink F, Leenen LPH, et al. The impact of prehospital time intervals on mortality in moderately and severely injured patients. J Trauma Acute Care Surg. 2021. https://doi.org/10.1097/TA. 0000000000003380 . 


\section{Authors and Affiliations}

Mitchell L. S. Driessen ${ }^{1}$ (D) J Jan C. van Ditshuizen ${ }^{2}$ • Job F. Waalwijk ${ }^{3} \cdot$ Gerrita van den Bunt $^{1}$ • Frank F. A. IJpma ${ }^{4}$. Inge H. F. Reininga ${ }^{5}$. Audrey A. Fiddelers ${ }^{3} \cdot$ Karin Habets $^{6} \cdot$ Paulien C. M. Homma $^{7}$ Marleen H. van den Berg ${ }^{8}$. Frank W. Bloemers ${ }^{9} \cdot$ Inger B. Schipper ${ }^{10} \cdot$ Luke P. H. Leenen $^{11} \cdot$ Mariska A. C. de Jongh $^{12}$

Jan C. van Ditshuizen

j.vanditshuizen@erasmusmc.nl

Job F. Waalwijk

jobwaalwijk@gmail.com

Gerrita van den Bunt

g.vandenbunt@1naz.nl

Frank F. A. IJpma

f.f.a.ijpma@umcg.nl

Inge H. F. Reininga

i.h.f.reininga@umcg.nl

Audrey A. Fiddelers

Audrey.fiddelers@nazl.nl

Karin Habets

Karin.Habets@radboudumc.nl

Paulien C. M. Homma

p.c.homma@amsterdamumc.nl

Marleen H. van den Berg

mh.vandenberg@amsterdamumc.nl

Frank W. Bloemers

fw.bloemers@amsterdamumc.nl

Inger B. Schipper

i.b.schipper@lumc.nl

Luke P. H. Leenen

1.p.h.leenen@umcutrecht.nl

Mariska A. C. de Jongh

m.d.jongh@nazb.nl
1 Dutch Network for Emergency Care (LNAZ), Utrecht, The Netherlands

2 Trauma Research Unit, Department of Surgery, Erasmus Medical Centre, Rotterdam, The Netherlands

3 Network of Acute Care Limburg (NAZL), Maastricht, The Netherlands

4 Department of Trauma Surgery, University Medical Centre Groningen, P.O Box 30.001, 9700 RB Groningen, Groningen, The Netherlands

5 Network of Acute Care Northern Netherlands (AZNN), Groningen, The Netherlands

6 Network of Acute Care Eastern Netherlands (AZO), Nijmegen, The Netherlands

7 Network of Acute Care Amsterdam (SpoedzorgNet), Amsterdam, The Netherlands

8 Network of Acute Care Northwest Netherlands (NAZNW), Amsterdam, The Netherlands

9 Department of Surgery, Amsterdam University Medical Centre, location VU, P.O. Box 1081 HV, Amsterdam, The Netherlands

10 Department of Trauma Surgery, Leiden University Medical Centre, P.O Box 9600, 2300 RC Leiden, The Netherlands

11 Department of Surgery, University Medical Centre Utrecht, P.O. Box 85500, 3508 GA Utrecht, The Netherlands

12 Brabant Trauma Registry, Network Emergency Care Brabant, Tilburg, The Netherlands 